\title{
Omitting Adjuvant Radiotherapy for Hormone Receptor-Positive Early-Stage Breast Cancer in Old Age: A Propensity Score Matched SEER Analysis
}

\author{
Yi-Jun Kim, MD ${ }^{1}$ \\ Kyung Hwan Shin, MD, PhD \\ Kyubo Kim, MD, PhD²
}

${ }^{1}$ Department of Radiation Oncology, Seoul National University College of Medicine, Seoul, ${ }^{2}$ Department of Radiation Oncology, Ewha Womans University College of Medicine, Seoul, Korea
Correspondence: Kyung Hwan Shin, MD, PhD Department of Radiation Oncology, Seoul National University College of Medicine, 103 Daehak-ro, Jongno-gu, Seoul 03080, Korea Tel: 82-2-2072-4767

Fax: 82-2-765-3317

E-mail: radiat@snu.ac.kr

Received March 16, 2018

Accepted May 8, 2018

Published Online May 10, 2018

\section{Purpose}

The purpose of this study was to investigate the non-inferiority of omitting radiotherapy (RT) after breast-conserving surgery (BCS) for hormone receptor (HR)-positive T1NO breast cancer in elderly women.

\section{Materials and Methods}

From 2004 to 2014, HR-positive T1NO breast cancer patients aged 50 years or older and receiving BCS were retrieved from the Surveillance, Epidemiology, and End Results 18 database. After propensity score matching between the no-RT and RT groups, univariate and multivariate analyses were performed. Identified prognostic factors were used to stratify the risk groups. In each risk group, 10-year cancer-specific survival (CSS) rates were compared between the no-RT and RT groups.

\section{Results}

After propensity score matching, the numbers of patients in the no-RT and RT groups were both 18,586 . For patients who satisfied both a tumor size of $1-10 \mathrm{~mm}$ and a tumor grade of $1-2$, omitting RT did not decrease the CSS rate at any age group, ranging from $\geq 50$ to $\geq 85$ years; for patients aged $\geq 50$ years, the 10 -year CSS rates in the no-RT and RT groups were $97.2 \%$ and $96.8 \%$, respectively (adjusted hazard ratio, $0.862 ; p=0.312$ ). However, for patients with a tumor size of 11-20 mm or tumor grade of 3-4, RT significantly increased the CSS rate irrespective of age.

\section{Conclusion}

RT after BCS for HR-positive T1NO breast cancer in elderly women might be omitted without causing a decrease in the CSS rate, but only in patients who satisfy both a small tumor size $(\leq 10 \mathrm{~mm})$ and low tumor grade (1-2).

\section{Introduction}

Adjuvant radiotherapy (RT) after breast-conserving surgery (BCS) for early-stage breast cancer patients of old age is controversial. Elderly patients have a high prevalence of comorbidity [1], and the rate of other-cause mortality increases with age [2]. Treatment-induced morbidity is also a considerable factor [3]. Early-stage breast cancer is associated with a relatively low mortality rate, and old age itself

\section{Key words}

Adjuvant radiotherapy, Aged, Breast neoplasms, SEER database, Estrogen receptors, Progesterone receptors, Tumor grade, Tumor size can be considered a low risk factor compared with young age in breast cancer patients [4]. Therefore, reduced treatments may not decrease the survival rate in elderly patients compared with conventional treatments [5]. Two randomized controlled trials (Cancer and Leukemia Group B [CALGB] 9343 [6] and PRIME II [7]) demonstrated no overall survival benefit from adjuvant RT in elderly patients with early-stage breast cancer after BCS.

In contrast, it appears that $\mathrm{RT}$ reduces local recurrence irrespective of age [8]. Many studies have shown that 
reduced treatments for elderly breast cancer patients significantly decreased the cancer-specific survival (CSS) rate $[2,9,10]$.

The National Comprehensive Cancer Network recommends selective administration of RT for women $\geq 70$ years of age with stage I breast cancer [11], while the International Society of Geriatric Oncology, European Society of Breast Cancer Specialists [12], and the 14th St. Gallen International Breast Cancer conference [13] recommend that RT should not be omitted regardless of age.

In clinical practice, there is a prevalent demand to reduce treatments in elderly patients $[14,15]$. These efforts to avoid over-treatment, however, may lead to under-treatment of elderly patients who can achieve survival benefits from conventional treatments. Therefore, a precise selection of the patient groups for RT is mandatory.

Accumulating evidence has indicated that the molecular subtype of breast cancer is a significant prognostic factor [16]. Especially, hormone receptor (HR)-positive breast cancer has a good prognosis compared with HR-negative cancer [17]. In addition, other prognostic factors, such as tumor size and grade, may also influence treatment outcomes. An optimal cut-off age to dichotomize patients into young and old groups is also needed.

In this study, a contemporary population-based cohort was examined to evaluate the effect of omitting adjuvant RT from the treatment of HR-positive early-stage breast cancer in elderly patients of various age groups by comparing CSS rates between no-RT and RT groups.

\section{Materials and Methods}

\section{Study population}

A list of patients was retrieved from the Surveillance, Epidemiology, and End Results (SEER) 18 database using the case listing option of the survival session of the SEER*Stat software program. Since the SEER data consists of de-identified data, this study was exempt from the Institutional Review Boards approval process.

The inclusion criteria were as follows: (1) pathologically confirmed breast cancer as the first primary cancer, (2) female, (3) aged $50 \geq$ years, (4) T1N0 stage, (5) HR (estrogen receptor or progesterone receptor)-positive cancer, (6) diagnosed from 2004 to 2014, (7) received BCS (surgery code 20-24), (8) received at least one regional lymph node examinations, (9) having information regarding adjuvant RT (no/ unknown, refused, or beam radiation after surgery), tumor grade, tumor size, and number of examined lymph nodes. Patients who were diagnosed by a death certificate only or autopsy only or patients without survival information were excluded.

In the SEER 18 database, four tumor grade scales were used: grade 1, well-differentiated; grade 2 , moderately differentiated; grade 3, poorly differentiated; and grade 4, undifferentiated or anaplastic. The Nottingham or BloomRichardson (BR) grade (1-3) has been additionally reported for breast cancer since 2010, and the BR grade from 1 to 3 was well matched with the previously reported tumor grade from 1 to 3 , respectively. As grade 4 was defined as undifferentiated or anaplastic differentiation, it was considered a poor prognosis.

\section{Propensity score matching}

Before propensity score matching, the no-RT and RT groups were compared using Pearson's chi-square test. One-to-one (1:1) propensity score matching between the no-RT and RT groups was conducted using a nearest neighbor algorithm. The matched variables were age, race, year of diagnosis, tumor grade, histology, tumor size, number of examined lymph nodes, chemotherapy (yes or no), insurance, and marital status.

After propensity score matching, a comparison of the variable distributions between the no-RT and RT groups was performed again using Pearson's chi-square test to evaluate the effectiveness of propensity score matching.

\section{Univariate and multivariate analyses}

After propensity score matching, univariate analysis of the effect of each variable on the 10-year CSS rate was performed using the Kaplan-Meier survival estimate followed by logrank test. Variables that were statistically significant with a p-value of $<0.05$ in the univariate analysis were then incorporated into a multivariate analysis. Multivariate analysis using the Cox proportional hazards model was performed to generate an adjusted hazard ratio (aHR) and a p-value for each variable. The variables with a notably high or low aHR and with statistical and clinical significances were selected and used to stratify risk groups.

\section{Comparison of 10-year CSS rates between the no-RT and RT groups}

In each classified risk group, the 10-year CSS rates were calculated and then compared between the no-RT and RT groups using the Kaplan-Meier method followed by log-rank test. A Cox proportional hazards model was used for multivariate analysis, incorporating all variables, to calculate the aHR for RT in each risk group. 
Table 1. Patient characteristics with HR-positive T1N0 breast cancer according to radiotherapy after BCS

\begin{tabular}{|c|c|c|c|c|c|c|}
\hline \multirow[b]{2}{*}{ Characteristic } & \multicolumn{2}{|c|}{ Before PSM } & \multirow[b]{2}{*}{ p-value ${ }^{a)}$} & \multicolumn{2}{|c|}{ After PSM } & \multirow[b]{2}{*}{ p-value ${ }^{a}$} \\
\hline & $\begin{array}{c}\text { No-RT } \\
(\mathrm{n}=18,586)\end{array}$ & $\begin{array}{c}\mathrm{RT} \\
(\mathrm{n}=72,863)\end{array}$ & & $\begin{array}{c}\text { No-RT } \\
(\mathrm{n}=18,586)\end{array}$ & $\begin{array}{c}\text { RT } \\
(n=18,586)\end{array}$ & \\
\hline \multicolumn{7}{|l|}{ Age (yr) } \\
\hline 50-59 & $4,205(22.6)$ & $23,808(32.7)$ & $<0.001$ & $4,205(22.6)$ & $4,147(22.3)$ & 0.557 \\
\hline $60-69$ & $4,911(26.4)$ & $28,401(39.0)$ & & $4,911(26.4)$ & $4,926(26.5)$ & \\
\hline $70-79$ & $5,913(31.8)$ & $16,506(22.7)$ & & $5,913(31.8)$ & $6,023(32.4)$ & \\
\hline$\geq 80$ & $3,557(19.1)$ & $4,148(5.7)$ & & 3,557 (19.1) & $3,490(18.8)$ & \\
\hline \multicolumn{7}{|l|}{ Race } \\
\hline White & $15,889(85.5)$ & $62,249(85.4)$ & $<0.001$ & $15,889(85.5)$ & $15,914(85.6)$ & 0.012 \\
\hline Black & $1,293(7.0)$ & $4,885(6.7)$ & & $1,293(7.0)$ & $1,278(6.9)$ & \\
\hline Other & $1,226(6.6)$ & $5,442(7.5)$ & & $1,226(6.6)$ & $1,271(6.8)$ & \\
\hline Unknown & $178(1.0)$ & $287(0.4)$ & & $178(1.0)$ & $123(0.7)$ & \\
\hline \multicolumn{7}{|l|}{ Year of diagnosis } \\
\hline 2004-2009 & $9,105(49.0)$ & $36,091(49.5)$ & 0.185 & $9,105(49.0)$ & $9,274(49.9)$ & 0.080 \\
\hline 2010-2014 & $9,481(51.0)$ & $36,772(50.5)$ & & $9,481(51.0)$ & $9,312(50.1)$ & \\
\hline \multicolumn{7}{|l|}{ Tumor grade } \\
\hline $1-2$ & $15,965(85.9)$ & $63,022(86.5)$ & 0.035 & $15,965(85.9)$ & $15,929(85.7)$ & 0.593 \\
\hline $3-4$ & 2,621 (14.1) & $9,841(13.5)$ & & 2,621 (14.1) & 2,657 (14.3) & \\
\hline \multicolumn{7}{|l|}{ Histology } \\
\hline IDC & $13,698(73.7)$ & $55,115(75.6)$ & $<0.001$ & $13,698(73.7)$ & $13,693(73.7)$ & 0.956 \\
\hline ILC & $1,256(6.8)$ & $5,502(7.6)$ & & $1,256(6.8)$ & $1,270(6.8)$ & \\
\hline Other & $3,632(19.5)$ & $12,246(16.8)$ & & $3,632(19.5)$ & $3,623(19.5)$ & \\
\hline \multicolumn{7}{|l|}{ Tumor size (mm) } \\
\hline $1-10$ & $8,862(47.7)$ & $35,484(48.7)$ & 0.013 & $8,862(47.7)$ & $8,772(47.2)$ & 0.350 \\
\hline $11-20$ & $9,724(52.3)$ & $37,379(51.3)$ & & $9,724(52.3)$ & $9,814(52.8)$ & \\
\hline \multicolumn{7}{|c|}{ No. of examined LNs } \\
\hline $1-4$ & $15,107(81.3)$ & $59,993(82.3)$ & 0.001 & $15,107(81.3)$ & $15,121(81.4)$ & 0.980 \\
\hline $5-9$ & $2,500(13.5)$ & $9,460(13.0)$ & & $2,500(13.5)$ & 2,487 (13.4) & \\
\hline$\geq 10$ & $979(5.3)$ & $3,410(4.7)$ & & $979(5.3)$ & $978(5.3)$ & \\
\hline \multicolumn{7}{|l|}{ Chemotherapy } \\
\hline No/Unknown & $16,826(90.5)$ & $63,288(86.9)$ & $<0.001$ & $16,826(90.5)$ & $16,828(90.5)$ & 0.972 \\
\hline Yes & $1,760(9.5)$ & $9,575(13.1)$ & & $1,760(9.5)$ & $1,758(9.5)$ & \\
\hline \multicolumn{7}{|l|}{ Insurance } \\
\hline Uninsured & $136(0.7)$ & $469(0.6)$ & 0.369 & $136(0.7)$ & $98(0.5)$ & 0.030 \\
\hline Insured & $13,895(74.8)$ & $54,393(74.7)$ & & $13,895(74.8)$ & $13,850(74.5)$ & \\
\hline Unknown & $4,555(24.5)$ & $18,001(24.7)$ & & $4,555(24.5)$ & $4,638(25.0)$ & \\
\hline \multicolumn{7}{|l|}{ Marital status } \\
\hline Married & $9,216(49.6)$ & $43,970(60.3)$ & $<0.001$ & $9,216(49.6)$ & $9,250(49.8)$ & 0.839 \\
\hline Other & $8,258(44.4)$ & $26,260(36.0)$ & & $8,258(44.4)$ & $8,249(44.4)$ & \\
\hline Unknown & $1,112(6.0)$ & $2,633(3.6)$ & & $1,112(6.0)$ & $1,087(5.8)$ & \\
\hline
\end{tabular}

Values are presented as number (\%). HR, hormone receptor; BCS, breast conserving surgery; PSM, propensity score matching; RT, radiotherapy; IDC, invasive ductal carcinoma; ILC, invasive lobular carcinoma; LN, lymph node. ${ }^{\text {a)Pearson's chi-square }}$ test.

\section{Statistical analysis}

The CSS was defined as the time from diagnosis to death attributable to this breast cancer. Individuals who were alive or dead due to other cause were considered to be censored. The SEER database offers the SEER cause-specific death classification data.

The R software (ver. 3.3.3, http://www.r-project.org/) 
package 'MatchIt' was used to perform propensity score matching, and packages 'survminer' and 'survival' were used to generate plots comparing the 10-year CSS rate between the no-RT and RT groups in each risk group. All other statistical calculations were performed using Stata software (Stata/MP ver. 14.2, StataCorp., College Station, TX).

\section{Ethical statement}

The Institutional Review Board (IRB) deemed this study using de-identified data to be exempt from IRB approval. Informed consent was not required because of the retrospective nature of the study. All procedures performed in studies were in accordance with the ethical standards of the institutional and / or national research committee and with the 1964 Helsinki declaration and its later amendments or comparable ethical standards.

\section{Results}

\section{Patient characteristics prior to propensity score matching}

All patients were HR-positive stage I breast cancer patients treated with BCS. The numbers of patients in the no-RT and RT groups were 18,586 (20.3\%) and 72,863 (79.7\%), respectively (Table 1). Patients who were not treated with adjuvant RT were older than those treated with RT. The numbers of patients $\geq 70$ years of age were 9,470 (50.9\%) and 20,654 $(28.4 \%)$ in the no-RT and RT groups, respectively $(\mathrm{p}<0.001)$. There were 7,462 (40.1\%), 8,503 (45.7\%), 2,567 (13.8\%), and $54(0.3 \%)$ patients in the no-RT group and 28,294 (38.8\%), $34,728(47.7 \%), 9,691(13.3 \%)$, and $150(0.2 \%)$ in the RT group with tumor grades $1,2,3$, and 4 , respectively $(\mathrm{p}<0.001)$. The majority of patients received 1-4 lymph node examinations in the no-RT (81.3\%) and RT groups (82.3\%); slightly more patients received $\geq 10$ lymph node examinations in the no-RT group than the RT group (5.3\% vs. $4.7 \%$ ). More patients received chemotherapy in the RT group than in the no-RT group (9.5\% vs. $13.1 \%$ ).

\section{Patient characteristics after propensity score matching}

Propensity score matching (1:1) between the no-RT and RT groups was performed. After matching, the numbers of patients in the no-RT and RT groups were the same $(18,586$ vs. 18,586), and only the variables race and insurance status showed a significantly difference between the groups. There were 5,913 $(31.8 \%)$ and 6,023 $(32.4 \%)$ patients aged 70-79 years and 3,557 (19.1\%) and 3,490 (18.8\%) patients aged $\geq 80$ years in the no-RT and RT groups, respectively $(\mathrm{p}=0.557)$ (Table 1).

\section{Univariate and multivariate analyses}

After propensity score matching, univariate analysis of the CSS rate was performed. Except for the year of diagnosis and number of examined lymph nodes, all variables showed significant prognostic power with $p<0.05$. Especially, old age, high tumor grade, tumor size $>10 \mathrm{~mm}$, and no-RT indicated a significantly poor prognosis (Table 2 ).

Multivariate analysis was performed after incorporating age, race, tumor grade, histology, tumor size, chemotherapy, $\mathrm{RT}$, insurance, and marital status. As a result, old age (aHR for 60-69 years compared with 50-59 years, $1.324 ; \mathrm{p}=0.028$; aHR for 70-79 years, 2.105; $\mathrm{p}<0.001$; aHR for $\geq 80$ years, 3.647; $\mathrm{p}<0.001$ ), high grade (aHR for grade 3-4, 2.212; $\mathrm{p}<0.001$ ), histologies which are neither invasive ductal carcinoma (IDC) nor invasive lobular carcinoma (ILC) (aHR for other histology compared with IDC, $0.688 ; \mathrm{p}<0.001$ ), and tumor size $>10 \mathrm{~mm}$ (aHR for 11-20 mm, 1.520; $<0.001$ ) were significantly correlated with a poor prognosis.

The worse CSS in older age may be related to the possibility that extremely elderly patients did not receive active treatments when recurrences occurred. The number of patients and the 10-year CSS rate for each histology after propensity score matching were as follows: IDC ( $\mathrm{n}=27,391 ; 10$-year CSS, $94.9 \%)$, ILC ( $\mathrm{n}=2,526,94.7 \%)$, infiltrating duct and lobular carcinoma $(n=2,548,96.1 \%)$, infiltrating duct mixed other types of carcinoma $(\mathrm{n}=1,538,96.2 \%)$, mucinous adenocarcinoma $(\mathrm{n}=1,398,97.4 \%)$, and tubular adenocarcinoma $(\mathrm{n}=682$, $97.5 \%$ ). The numbers of patients in the other histologies were less than 200 per histology. The survivals of major histologies other than pure IDC and ILC were favorable. Especially the good prognoses of mucinous adenocarcinoma and tubular adenocarcinoma seemed to be the reasons of the significantly favorable CSS in the histologies except IDC and ILC.

Patients treated with RT showed a significantly favorable prognosis (aHR, 0.622; $\mathrm{p}<0.001$ ), while patients treated with chemotherapy were correlated with a significantly poor prognosis (aHR, 1.566; $\mathrm{p}<0.001)$. A higher proportion of patients who received chemotherapy had a tumor grade of $3-4(1,498$ of 3,518 [42.6\%]) compared with those who did not receive chemotherapy $(3,780$ of $33,654[11.2 \%])$, suggesting that a high tumor grade may influence the adverse effect of chemotherapy on the CSS rate.

\section{Comparison of 10-year CSS rates between the no-RT and RT groups}

The 10-year CSS rates were compared between the no-RT and RT groups in each risk group stratified by significantly 
Table 2. Univariate and multivariate analyses of the CSS rate in HR-positive T1N0 breast cancer after PSM

\begin{tabular}{|c|c|c|c|c|c|c|}
\hline \multirow{2}{*}{ Characteristic } & \multicolumn{3}{|c|}{ Univariate } & \multicolumn{3}{|c|}{ Multivariate } \\
\hline & 10-Year CSS (\%) & $95 \% \mathrm{CI}$ & p-value ${ }^{a)}$ & aHR & $95 \% \mathrm{CI}$ & p-value ${ }^{b)}$ \\
\hline \multicolumn{7}{|l|}{ All } \\
\hline \multicolumn{7}{|l|}{ Age (yr) } \\
\hline 50-59 & 96.3 & $95.3-97.2$ & $<0.001$ & Reference & & \\
\hline $60-69$ & 96.4 & $95.5-97.1$ & & 1.324 & $1.030-1.701$ & 0.028 \\
\hline $70-79$ & 95.5 & $94.6-96.2$ & & 2.105 & $1.651-2.684$ & $<0.001$ \\
\hline$\geq 80$ & 91.2 & $89.2-92.8$ & & 3.647 & $2.835-4.691$ & $<0.001$ \\
\hline \multicolumn{7}{|l|}{ Race } \\
\hline White & 95.2 & $94.7-95.7$ & 0.018 & Reference & & \\
\hline Black & 94.2 & $92.1-95.8$ & & 1.232 & $0.935-1.625$ & 0.139 \\
\hline Other & 96.7 & $94.0-98.2$ & & 0.692 & $0.473-1.012$ & 0.058 \\
\hline Unknown & 96.7 & $89.6-99.0$ & & 0.900 & $0.289-2.808$ & 0.857 \\
\hline \multicolumn{7}{|l|}{ Year of diagnosis } \\
\hline 2004-2009 & 98.2 & 98.0-98.4 & 0.756 & & & \\
\hline 2010-2014 & 98.6 & 98.3-98.9 & & NA & & \\
\hline \multicolumn{7}{|l|}{ Grade } \\
\hline $1-2$ & 95.9 & $95.3-96.3$ & $<0.001$ & Reference & & \\
\hline 3-4 & 92.1 & $90.5-93.4$ & & 2.212 & $1.853-2.640$ & $<0.001$ \\
\hline \multicolumn{7}{|l|}{ Histology } \\
\hline IDC & 94.9 & $94.3-95.5$ & 0.006 & Reference & & \\
\hline ILC & 94.7 & $91.7-96.6$ & & 0.926 & $0.677-1.267$ & 0.631 \\
\hline Other & 96.5 & $95.5-97.3$ & & 0.688 & $0.557-0.851$ & 0.001 \\
\hline \multicolumn{7}{|l|}{ Tumor size (mm) } \\
\hline $1-10$ & 96.7 & $96.1-97.2$ & $<0.001$ & Reference & & \\
\hline $11-20$ & 94.1 & $93.2-94.8$ & & 1.520 & $1.291-1.790$ & $<0.001$ \\
\hline \multicolumn{7}{|c|}{ No. of examined LNs } \\
\hline $1-4$ & 95.4 & $94.8-95.9$ & 0.064 & & & \\
\hline $5-9$ & 94.9 & $93.4-96.0$ & & NA & & \\
\hline$\geq 10$ & 94.8 & $93.0-96.1$ & & & & \\
\hline \multicolumn{7}{|l|}{ Chemotherapy } \\
\hline No/Unknown & 95.4 & $94.8-95.9$ & 0.004 & Reference & & \\
\hline Yes & 94.4 & $92.6-95.7$ & & 1.566 & $1.226-2.001$ & $<0.001$ \\
\hline \multicolumn{7}{|c|}{ Adjuvant radiotherapy } \\
\hline No/Unknown & 94.4 & $93.5-95.1$ & $<0.001$ & Reference & & \\
\hline Yes & 96.1 & $95.5-96.7$ & & 0.622 & $0.533-0.725$ & $<0.001$ \\
\hline \multicolumn{7}{|l|}{ Insurance } \\
\hline Uninsured & 97.8 & $93.1-99.3$ & 0.020 & Reference & & \\
\hline Insured & 98.3 & $98.1-98.5$ & & 0.590 & $0.219-1.590$ & 0.297 \\
\hline Unknown & 98.0 & $97.7-98.3$ & & 0.767 & $0.284-2.069$ & 0.600 \\
\hline \multicolumn{7}{|l|}{ Marital status } \\
\hline Married & 95.8 & $95.1-96.4$ & $<0.001$ & Reference & & \\
\hline Other & 94.6 & 93.9-95.3 & & 1.186 & $1.010-1.393$ & 0.037 \\
\hline Unknown & 95.7 & 91.4-97.9 & & 0.753 & $0.492-1.153$ & 0.193 \\
\hline
\end{tabular}

CSS, cancer-specific survival; HR, hormone receptor; PSM, propensity score matching; CI, confidence interval; aHR, adjusted hazard ratio; NA, not applicable; IDC, invasive ductal carcinoma; ILC, invasive lobular carcinoma; LN, lymph node. ${ }^{a}$ Kaplan-Meier survival estimates compared by log-rank test, ${ }^{b}$ Cox proportional hazards model. 
Table 3. CSS rate in HR-positive T1N0 breast cancer according to age, size, and grade after PSM

\begin{tabular}{|c|c|c|c|c|c|c|c|c|c|c|}
\hline \multirow{3}{*}{ Age (yr) } & \multicolumn{7}{|c|}{ Univariate } & \multicolumn{3}{|c|}{ Multivariate } \\
\hline & \multicolumn{3}{|c|}{ No-RT } & \multicolumn{3}{|c|}{ RT } & \multirow{2}{*}{ p-value } & \multirow{2}{*}{$\begin{array}{l}\text { aHR } \\
\text { of RT }\end{array}$} & \multirow{2}{*}{$95 \% \mathrm{CI}$} & \multirow{2}{*}{ p-value ${ }^{\text {b) }}$} \\
\hline & No. & 10-Year CSS & $95 \% \mathrm{CI}$ & No. & 10-Year CSS & $95 \% \mathrm{CI}$ & & & & \\
\hline \multicolumn{11}{|c|}{ Tumor size $1-10 \mathrm{~mm}$, grade $1-2$} \\
\hline$\geq 50$ & 8,047 & 97.2 & $96.4-97.8$ & 7,915 & 96.8 & $95.8-97.6$ & 0.349 & 0.862 & $0.646-1.150$ & 0.312 \\
\hline$\geq 55$ & 7,361 & 96.9 & $96.0-97.6$ & 7,257 & 96.7 & $95.6-97.5$ & 0.213 & 0.825 & $0.614-1.108$ & 0.201 \\
\hline$\geq 60$ & 6,547 & 96.6 & $95.5-97.4$ & 6,427 & 96.7 & $95.6-97.5$ & 0.177 & 0.801 & $0.590-1.088$ & 0.156 \\
\hline$\geq 65$ & 5,563 & 96.3 & $95.1-97.3$ & 5,375 & 96.4 & 95.1-97.4 & 0.214 & 0.807 & $0.585-1.112$ & 0.190 \\
\hline$\geq 70$ & 4,472 & 96.3 & $95.0-97.3$ & 4,353 & 96.1 & $94.5-97.2$ & 0.268 & 0.819 & $0.580-1.156$ & 0.256 \\
\hline$\geq 75$ & 2,955 & 95.7 & $93.7-97.0$ & 2,613 & 95.0 & $92.5-96.7$ & 0.392 & 0.838 & $0.558-1.258$ & 0.393 \\
\hline$\geq 80$ & 1,562 & 94.2 & $90.0-96.6$ & 1,400 & 93.4 & $88.5-96.2$ & 0.974 & 0.984 & $0.581-1.666$ & 0.952 \\
\hline$\geq 85$ & 502 & 93.6 & $87.0-96.9$ & 289 & 95.7 & $90.8-98.0$ & 0.608 & 0.792 & $0.312-2.012$ & 0.625 \\
\hline \multicolumn{11}{|c|}{ Tumor size $11-20 \mathrm{~mm}$, grade $1-2$} \\
\hline$\geq 50$ & 7,918 & 93.4 & $91.7-94.7$ & 8,014 & 95.9 & $94.8-96.8$ & $<0.001$ & 0.591 & $0.468-0.746$ & $<0.001$ \\
\hline$\geq 55$ & 7,056 & 92.4 & $90.5-94.0$ & 7,195 & 95.8 & $94.7-96.8$ & $<0.001$ & 0.550 & $0.433-0.699$ & $<0.001$ \\
\hline$\geq 60$ & 6,112 & 92.7 & $90.8-94.2$ & 6,223 & 95.6 & $94.2-96.7$ & $<0.001$ & 0.591 & $0.468-0.746$ & $<0.001$ \\
\hline$\geq 65$ & 5,141 & 91.4 & 88.9-93.3 & 5,177 & 95.0 & $93.3-96.3$ & $<0.001$ & 0.543 & $0.421-0.700$ & $<0.001$ \\
\hline$\geq 70$ & 4,053 & 90.3 & 87.4-92.6 & 4,142 & 94.9 & $93.1-96.2$ & $<0.001$ & 0.513 & $0.385-0.685$ & $<0.001$ \\
\hline$\geq 75$ & 2,854 & 88.7 & $85.1-91.6$ & 2,662 & 94.1 & $91.7-95.8$ & $<0.001$ & 0.497 & $0.359-0.687$ & $<0.001$ \\
\hline$\geq 80$ & 1,659 & 86.8 & $80.5-91.2$ & 1,691 & 92.2 & $88.2-94.8$ & 0.001 & 0.527 & $0.362-0.769$ & 0.001 \\
\hline$\geq 85$ & 651 & 75.4 & $57.5-86.6$ & 382 & 87.8 & $64.0-96.3$ & 0.021 & 0.477 & $0.241-0.942$ & 0.033 \\
\hline \multicolumn{11}{|c|}{ Tumor size $1-10$ mm, grade 3-4 } \\
\hline$\geq 50$ & 815 & 90.9 & $85.1-94.5$ & 857 & 96.4 & $94.0-97.9$ & 0.005 & 0.387 & $0.207-0.720$ & 0.003 \\
\hline$\geq 55$ & 697 & 89.8 & $82.7-94.1$ & 738 & 96.2 & $93.6-97.8$ & 0.006 & 0.388 & $0.204-0.738$ & 0.004 \\
\hline$\geq 60$ & 555 & 88.1 & $78.9-93.4$ & 598 & 95.7 & $92.5-97.5$ & 0.008 & 0.391 & $0.200-0.765$ & 0.006 \\
\hline$\geq 65$ & 439 & 85.3 & $73.8-92.1$ & 481 & 94.8 & $90.9-97.1$ & 0.009 & 0.392 & $0.195-0.789$ & 0.009 \\
\hline$\geq 70$ & 316 & 86.1 & $70.2-93.9$ & 355 & 94.4 & $89.6-97.0$ & 0.061 & 0.440 & $0.198-0.980$ & 0.044 \\
\hline$\geq 75$ & 206 & 83.4 & $62.9-93.2$ & 218 & 94.8 & $88.4-97.7$ & 0.063 & 0.343 & $0.126-0.935$ & 0.037 \\
\hline$\geq 80$ & 102 & 86.5 & $70.5-94.2$ & 131 & 94.2 & $84.8-97.8$ & 0.077 & 0.337 & $0.094-1.201$ & 0.093 \\
\hline$\geq 85$ & 31 & 89.3 & $60.2-97.5$ & 22 & NA & NA & 0.175 & NA & NA & NA \\
\hline \multicolumn{11}{|c|}{ Tumor size $11-20 \mathrm{~mm}$, grade $3-4$} \\
\hline$\geq 50$ & 1,806 & 88.5 & $85.0-91.2$ & 1,800 & 93.8 & $91.4-95.6$ & $<0.001$ & 0.524 & $0.373-0.735$ & $<0.001$ \\
\hline$\geq 55$ & 1,490 & 87.8 & $84.7-90.4$ & 1,513 & 93.9 & $91.2-95.8$ & $<0.001$ & 0.480 & $0.333-0.693$ & $<0.001$ \\
\hline$\geq 60$ & 1,167 & 86.7 & $82.6-89.8$ & 1,191 & 93.9 & $91.2-95.8$ & 0.002 & 0.519 & $0.348-0.775$ & 0.001 \\
\hline$\geq 65$ & 888 & 85.3 & $80.2-89.1$ & 915 & 93.0 & 89.5-95.4 & 0.005 & 0.522 & $0.336-0.810$ & 0.004 \\
\hline$\geq 70$ & 629 & 83.8 & $77.3-88.5$ & 663 & 92.4 & 87.5-95.4 & 0.004 & 0.457 & $0.276-0.757$ & 0.002 \\
\hline$\geq 75$ & 413 & 81.9 & $74.2-87.5$ & 423 & 90.9 & $82.3-95.4$ & 0.007 & 0.449 & $0.247-0.816$ & 0.009 \\
\hline$\geq 80$ & 234 & 77.8 & $65.1-86.3$ & 268 & 89.2 & $70.9-96.3$ & 0.004 & 0.308 & $0.137-0.693$ & 0.004 \\
\hline$\geq 85$ & 101 & 70.4 & $45.0-85.7$ & 60 & 93.3 & $61.3-99.0$ & 0.015 & 0.015 & $0.001-0.230$ & 0.003 \\
\hline
\end{tabular}

CSS, cancer-specific survival; HR, hormone receptor; PSM, propensity score matching; RT, radiotherapy; CI, confidence interval; aHR, adjusted hazard ratio; NA, not applicable. ${ }^{\mathrm{a}}$ Kaplan-Meier survival estimates compared by log-rank test, ${ }^{\text {b) }}$ Cox proportional hazards model incorporating adjuvant radiotherapy (RT), age, race, year of diagnosis, histology, number of examined lymph nodes, chemotherapy, insurance, and marital status.

prognostic variables in a multivariate analysis (age, tumor grade, and tumor size) (Table 3). Tumor size (1-10 mm vs. 11-20 $\mathrm{mm}$ ) and tumor grade (1-2 vs. 3-4) were used to generate four $(2 \times 2)$ risk groups. The CSS rate was compared between the no-RT and RT groups in each risk group accord- ing to age group $(\geq 50, \geq 55, \geq 60, \geq 65, \geq 70, \geq 75, \geq 80$, and $\geq$ 85 years).

In the risk group with a tumor size of 1-10 $\mathrm{mm}$ and tumor grade of 1-2, no significant difference in CSS was observed between the no-RT and RT groups in any of the age groups. 
Size $1-10 \mathrm{~mm} \&$ grade $1-2$

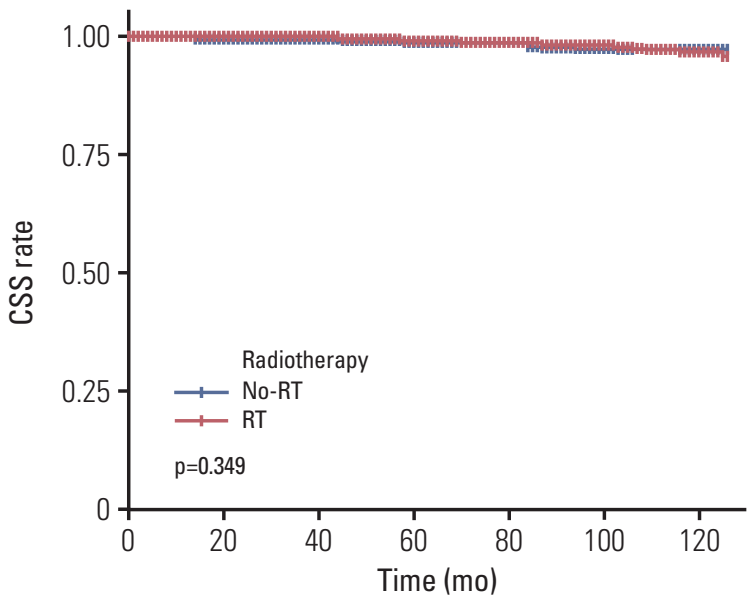

No. at risk

$\begin{array}{llllllll}\text { No-RT } & 8,047 & 6,151 & 4,626 & 3,292 & 2,079 & 1,134 & 353\end{array}$

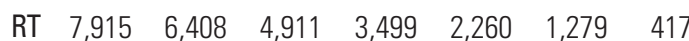

A

Size 11-20 mm \& grade 1-2

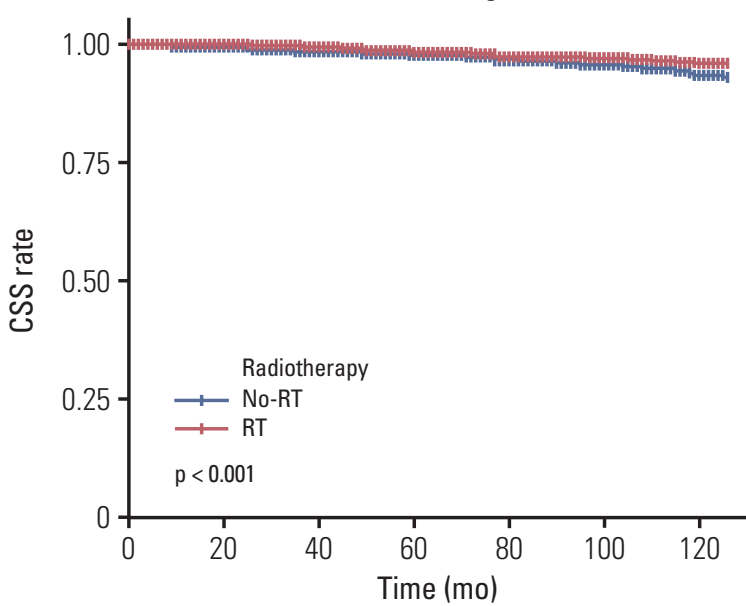

No. at risk

$\begin{array}{rrrrrrrr}\text { No-RT } & 7,918 & 6,068 & 4,665 & 3,357 & 2,139 & 1,111 & 332 \\ \text { RT } & 8,014 & 6,458 & 5,056 & 3,635 & 2,399 & 1,329 & 443\end{array}$

Size 1-10 mm \& grade 3-4

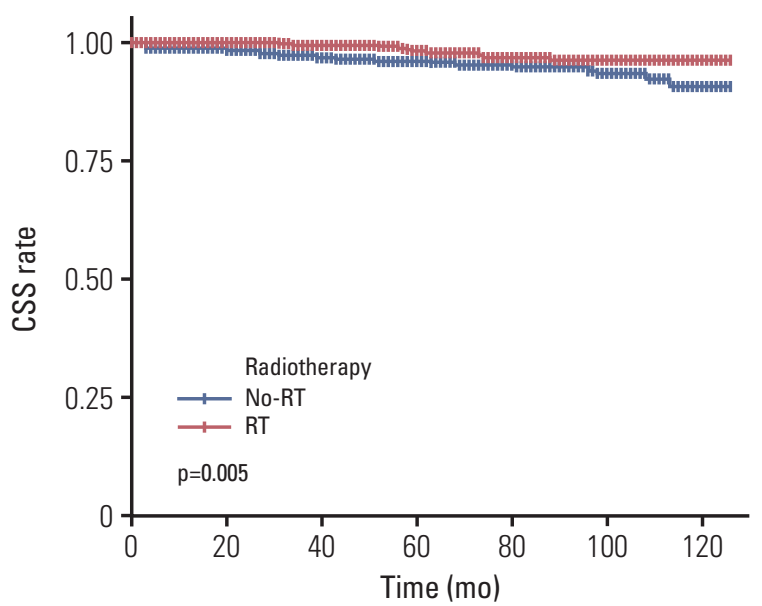

No. at risk

$\begin{array}{rlllllll}\text { No-RT } & 815 & 635 & 486 & 360 & 229 & 119 & 32 \\ \text { RT } & 857 & 708 & 544 & 425 & 279 & 155 & 53\end{array}$

C

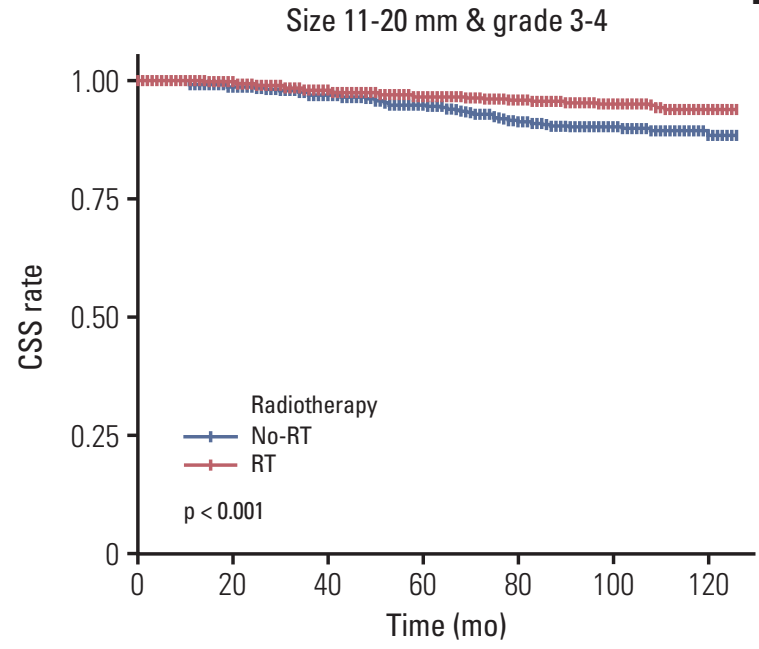

No. at risk

$\begin{array}{rrrrrrrr}\text { No-RT } & 1,806 & 1,441 & 1,122 & 814 & 521 & 289 & 86 \\ \text { RT } & 1,800 & 1,444 & 1,136 & 867 & 583 & 319 & 104\end{array}$

Fig. 1. Kaplan-Meier estimates of the cancer-specific survival (CSS) rate of patients with hormone receptor-positive T1N0 breast cancer aged $\geq 50$ years according to whether adjuvant radiotherapy $(\mathrm{RT})$ after breast conserving surgery was received or not. (A) Tumor size 1-10 mm and tumor grade 1-2. (B) Tumor size 11-20 mm and tumor grade 1-2. (C) Tumor size 1-10 $\mathrm{mm}$ and tumor grade 3-4. (D) Tumor size 11-20 $\mathrm{mm}$ and tumor grade 3-4.

The 10-year CSS rates were $97.2 \%$ and $96.8 \%$ in the no-RT and RT groups, respectively, among patients $\geq 50$ years of age ( $\mathrm{p}=0.349)$ (Fig. 1). In a multivariate analysis incorporating adjuvant RT, age, race, year of diagnosis, histology, number of examined lymph nodes, chemotherapy, insurance, and marital status, the aHR for RT was not statistically significant regardless of age (age $\geq 50$ years: aHR, $0.862 ; 95 \%$ confidence interval [CI], 0.646 to 1.150; $\mathrm{p}=0.312$ ) (Figs. 1 and 2). 
Size 1-10 mm \& grade 1-2

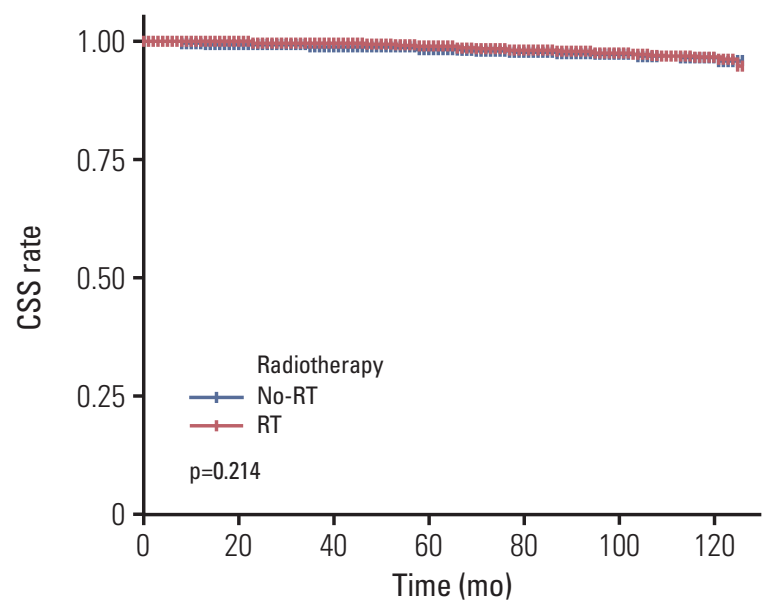

No. at risk

$\begin{array}{llllllll}\text { No-RT } & 5,563 & 4,173 & 3,043 & 2,081 & 1,275 & 671 & 192\end{array}$

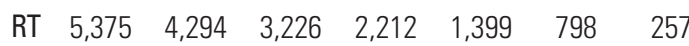

Size 1-10 mm \& grade 3-4

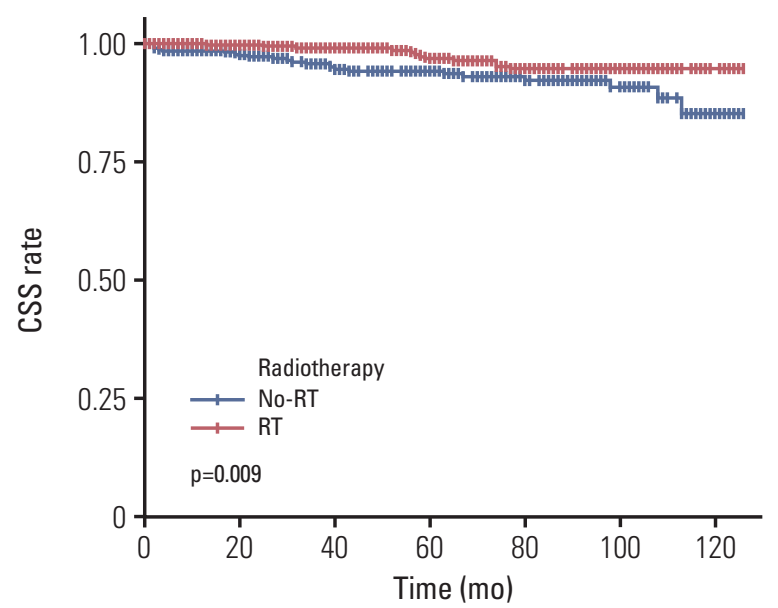

No. at risk

$\begin{array}{rrrrrrrr}\text { No-RT } & 439 & 329 & 237 & 175 & 110 & 64 & 14 \\ \text { RT } & 481 & 392 & 296 & 222 & 142 & 80 & 31\end{array}$

C
A

Size $11-20 \mathrm{~mm} \&$ grade $1-2$

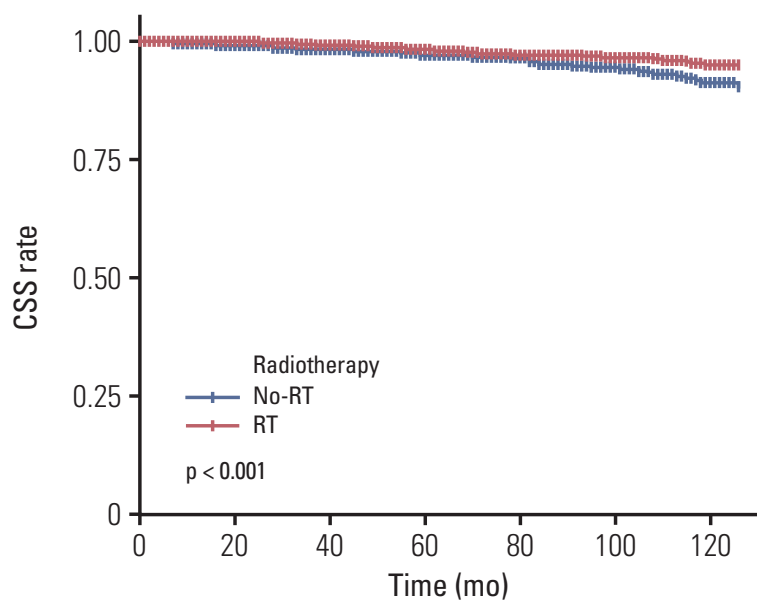

No. at risk

$\begin{array}{rrrrrrrr}\text { No-RT } & 5,141 & 3,865 & 2,860 & 1,963 & 1,186 & 578 & 152 \\ \text { RT } & 5,177 & 4,142 & 3,192 & 2,193 & 1,413 & 762 & 247\end{array}$
Size 11-20 mm \& grade 3-4

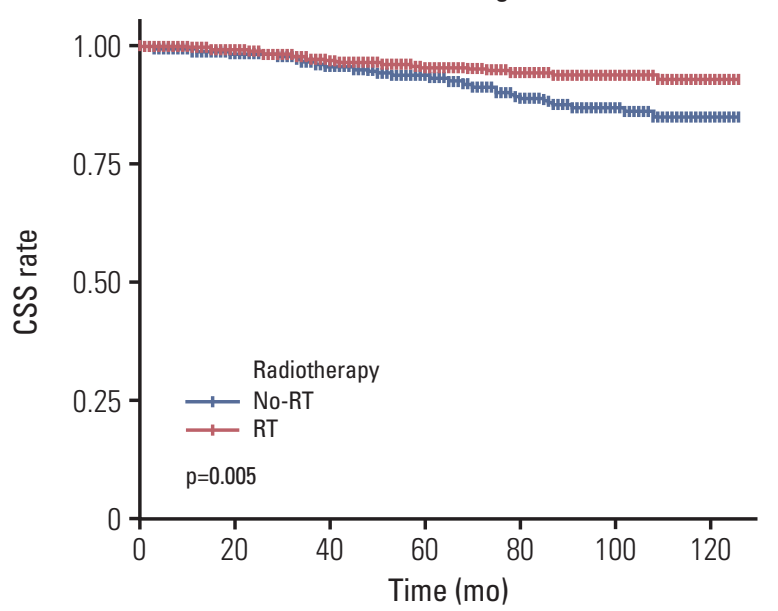

No. at risk

$\begin{array}{rrrrrrrr}\text { No-RT } & 888 & 689 & 516 & 351 & 211 & 112 & 28 \\ \text { RT } & 915 & 711 & 539 & 383 & 250 & 135 & 41\end{array}$

Fig. 2. Kaplan-Meier estimates of the cancer-specific survival (CSS) rate of patients with hormone receptor-positive T1N0 breast cancer aged $\geq 65$ years according to whether adjuvant radiotherapy (RT) after breast conserving surgery was received or not. (A) Tumor size 1-10 mm and tumor grade 1-2. (B) Tumor size 11-20 mm and tumor grade 1-2. (C) Tumor size 1-10 $\mathrm{mm}$ and tumor grade 3-4. (D) Tumor size 11-20 $\mathrm{mm}$ and tumor grade 3-4.

As shown in Figs. 1 and 2, the declining patient number over time reflects death from any causes. The number of patients in the no-RT group decreased more rapidly compared to that in the RT group even in the risk group with a tumor size of 1-10 mm and tumor grade of 1-2, suggesting that patients with high co-morbidity may have received less adjuvant RT. However, there was no difference in breast cancer-related mortality (CSS) in the risk group with a tumor 
size of 1-10 mm and tumor grade of 1-2.

In the patients aged $\geq 50$ years with a tumor size of $11-20$ $\mathrm{mm}$ and tumor grade of 1-2, the 10-year CSS rates were $93.4 \%$ and $95.9 \%$ in the no-RT and RT groups, respectively $(\mathrm{p}<0.001)$. This favorable prognosis in the RT group was seen in every age group evaluated. Multivariate analyses demonstrated that RT increased the CSS rate significantly after adjusting for other prognostic variables (age $\geq 50$ years: aHR for RT, $0.591 ; 95 \%$ CI, 0.468 to 0.746 ; $\mathrm{p}<0.001$ ).

In the patients with a tumor size of $1-10 \mathrm{~mm}$ and tumor grade of 3-4, the 10-year CSS rates were $90.9 \%$ and $96.4 \%$ in the no-RT and RT groups, respectively $(\mathrm{p}=0.005)$. Although RT did not show a significant survival benefit for patients of very old age in the multivariate analysis ( $\geq 80$ and $\geq 85$ years), these CSS rates were considerably different between the no-RT and RT groups, with a low aHR (age $\geq 80$ years: aHR of RT, $0.337 ; 95 \%$ CI, 0.094 to 1.201; $\mathrm{p}=0.093$ ), suggesting that the relatively small sample size of very old age patients may have contributed to the lack of statistical significance.

In patients with a tumor size of $11-20 \mathrm{~mm}$ and tumor grade of 3-4, a significant improvement in the 10-year CSS rate by RT was observed for patients aged $\geq 50$ years $(88.5 \%$ and $93.8 \%$ in the no-RT and RT groups, respectively; $\mathrm{p}<0.001$ ). According to multivariate analysis, RT increased CSS significantly in all age groups (age $\geq 50$ years: aHR for RT, 0.524; 95\% CI, 0.373 to $0.735 ; \mathrm{p}<0.001$ ) (Figs. 1 and 2).

\section{Discussion}

Our study demonstrated that omitting RT in the treatment of patients aged $\geq 50$ years with HR-positive early-stage breast cancer (T1N0) after BCS did not decrease the 10-year CSS rate when both conditions of tumor size $\leq 10 \mathrm{~mm}$ and low tumor grade (1-2) were satisfied. RT significantly increased the 10-year CSS rate of patients with a tumor size $>10 \mathrm{~mm}$ or a high tumor grade (3-4) irrespective of age, suggesting that omitting RT may be a reasonable option for elderly patients, but only in those with a tumor size $\leq 10 \mathrm{~mm}$ and tumor grade $\leq 2$.

Adjuvant RT after BCS has long been a dogma, even for elderly patients, as a significant 10 -year recurrence-free survival benefit from RT has been reported in all age groups [18]. However, as the treatment outcomes in breast cancer have improved [19], the possibility of omitting RT in elderly patients is being examined with caution.

Based on the prognostic value of the molecular subtype even in early-stage breast cancer [20-22], two randomized trials have evaluated RT in elderly patients with HR-positive, early-stage breast cancer (CALGB 9343 [6] and PRIME II [7]).
The patients were aged $\geq 70$ years and $\geq 65$ years in the CALGB 9343 and PRIME II trials, respectively. In these trials, RT significantly decreased the 10-year locoregional recurrence rate from $10 \%$ to $2 \%$ and the 5 -year ipsilateral breast tumor recurrence rate from $4.1 \%$ to $1.3 \%$. Although RT decreased the locoregional recurrence rate in both trials, this effect did not lead to an overall survival benefit in elderly patients with limited life expectancies in either trial, suggesting that the omission of RT can be considered for select patients. However, the selection of such patients in clinical practice may require stricter risk assessments to avoid undertreatment of elderly patients.

Moreover, the tumor grade was not reported in the CALGB 9343, and the number of patients with tumor grade 3 was limited in PRIME II (23 (3.5\%) in the no-RT group and $54(2.0 \%)$ in the RT group). Tumor grade has prognostic value, even in the molecular era, with accumulating evidence showing that grade is strongly related to tumor behavior [23].

Considering the prognostic importance of tumor grade, the American Joint Committee on Cancer staging system, eighth edition, incorporated tumor grade to refine prognosis [24]. For HR-positive early-stage breast cancer, which has limited prognostic factors (tumor size $\leq 20 \mathrm{~mm}$, no lymph node involvement, and HR positivity), the importance of the tumor grade as a prognostic factor may increase. In our study, tumor grade was identified as a significant prognostic factor for HR-positive early-stage breast cancer patients, with one of the highest aHRs (2.212) in the multivariate analysis. Therefore, prognostic analysis according to tumor grade would be useful for determining whether to administer RT to elderly patients.

Our study also demonstrated that tumor size is another significant factor determining a CSS benefit from RT; RT increased CSS in patients with a tumor size $>10 \mathrm{~mm}$ (T1c) but not in those with a tumor size $\leq 10 \mathrm{~mm}$ (T1a or T1b) and a low tumor grade (1-2). A larger tumor size implies a higher tumor burden and insufficiently wide excision, resulting in prognostic differences, even among early-stage breast cancer patients with a small tumor size [25]. Several studies have demonstrated that tumor size may not be a main determinant of prognosis for early-stage breast cancer patients $[26,27]$. However, in a confined molecular subtype setting (HR positivity), tumor size appears to be a significant prognosticator, especially when deciding whether to omit adjuvant RT, which is a conventional treatment administered after BCS. Therefore, in HR-positive early-stage breast cancer with a tumor size $\leq 20 \mathrm{~mm}$, omitting RT may cause adverse effects unless the tumor size is substantially small (e.g., $\leq 10$ $\mathrm{mm})$.

Studies on elderly breast cancer patients used various cutoffs to define old age, including $>50$ years [28], 55 years [14], 
65 years [7-9], or 70 years [6]. In our study, no cut-off age was identified that significantly divided the treatment outcomes. Every age group showed similar results in terms of RT effects. One study demonstrated that breast cancer patients aged $\geq 80$ years received less aggressive treatment and had higher cancer-specific mortality compared with younger patients [10]. Therefore, even for very old patients, omitting RT based on age should be avoided unless the life expectancy is obviously short and comorbidities are present, and only low risk groups, according to HR, tumor size, and tumor grade, should consider RT omission as an option.

Hepel and Wazer [29] suggested that the omission of RT is an option for patients with a life expectancy $<5$ years or for patients with a low risk of local recurrence or distant metastasis. However, for high-risk patients, such as those with a high tumor grade, lymphovascular invasion, or human epidermal growth factor receptor 2 positivity, RT is strongly recommended. In the same manner, our study supports that HR positivity, tumor grade, and tumor size should be considered in the decision to omit RT in the treatment of elderly patients.

As the SEER 18 database does not provide information on hormone therapy, the effect of hormone therapy could not be evaluated. However, as hormone therapy is a standard treatment for HR-positive breast cancer patients, the majority of HR-positive patients are assumed to receive hormone therapy. Information on local recurrence and distant metastasis was not available. Therefore, the possibility of a decrease in the recurrence-free survival rate without a decrease in the CSS rate in low-risk, early-stage breast cancer indicates that the omission of RT in relatively young patients should be considered with caution. Information on performance status, comorbidities, lymphovascular invasion, surgical margins, human epidermal growth factor receptor 2 status, RT dose, and fraction was also not available.

In conclusion, in elderly patients with HR-positive earlystage breast cancer (T1N0), omitting RT did not decrease the CSS rate of patients with a tumor size $\leq 10 \mathrm{~mm}$ and tumor grade $\leq 2$, suggesting that omitting $R T$ is a possible treatment option for these patients. For patients with a tumor size $>10$ mm or tumor grade $3-4$, RT significantly increased the CSS rate regardless of age. Therefore, even in elderly patients with HR-positive early-stage breast cancer, omitting RT should be considered with caution.

\section{Conflicts of Interest}

Conflict of interest relevant to this article was not reported.

\section{Acknowledgments}

This research did not receive any specific grant from funding agencies in the public, commercial, or not-for-profit sectors.

\section{References}

1. Girones R, Torregrosa D, Diaz-Beveridge R. Comorbidity, disability and geriatric syndromes in elderly breast cancer survivors: results of a single-center experience. Crit Rev Oncol Hematol. 2010;73:236-45.

2. van de Water W, Markopoulos C, van de Velde CJ, Seynaeve C, Hasenburg A, Rea D, et al. Association between age at diagnosis and disease-specific mortality among postmenopausal women with hormone receptor-positive breast cancer. JAMA. 2012;307:590-7.

3. Bovelli D, Plataniotis G, Roila F; ESMO Guidelines Working Group. Cardiotoxicity of chemotherapeutic agents and radiotherapy-related heart disease: ESMO Clinical Practice Guidelines. Ann Oncol. 2010; 21 Suppl 5:v277-82.

4. Arvold ND, Taghian AG, Niemierko A, Abi Raad RF, Sreedhara M, Nguyen PL, et al. Age, breast cancer subtype approximation, and local recurrence after breast-conserving therapy. J Clin Oncol. 2011;29:3885-91.

5. Bastiaannet E, Portielje JE, van de Velde CJ, de Craen AJ, van der Velde S, Kuppen PJ, et al. Lack of survival gain for elderly women with breast cancer. Oncologist. 2011;16:415-23.
6. Hughes KS, Schnaper LA, Bellon JR, Cirrincione CT, Berry DA, McCormick B, et al. Lumpectomy plus tamoxifen with or without irradiation in women age 70 years or older with early breast cancer: long-term follow-up of CALGB 9343. J Clin Oncol. 2013;31:2382-7.

7. Kunkler IH, Williams LJ, Jack WJ, Cameron DA, Dixon JM; PRIME II investigators. Breast-conserving surgery with or without irradiation in women aged 65 years or older with early breast cancer (PRIME II): a randomised controlled trial. Lancet Oncol. 2015;16:266-73.

8. Potter R, Gnant M, Kwasny W, Tausch C, Handl-Zeller L, Pakisch B, et al. Lumpectomy plus tamoxifen or anastrozole with or without whole breast irradiation in women with favorable early breast cancer. Int J Radiat Oncol Biol Phys. 2007;68:334-40.

9. Bastiaannet E, Liefers GJ, de Craen AJ, Kuppen PJ, van de Water W, Portielje JE, et al. Breast cancer in elderly compared to younger patients in the Netherlands: stage at diagnosis, treatment and survival in 127,805 unselected patients. Breast Cancer Res Treat. 2010;124:801-7. 
10. Schonberg MA, Marcantonio ER, Li D, Silliman RA, Ngo L, McCarthy EP. Breast cancer among the oldest old: tumor characteristics, treatment choices, and survival. J Clin Oncol. 2010;28:2038-45.

11. National Comprehensive Cancer Network Clnical Practice Guidelines in Oncology, Older Adult Oncology, (NCCN Guidelines Version 2.2017) [Internet]. Fort Washington, PA: National Comprehensive Cancer Network; 2017 [cited 2018 May 4]. Available from: https://www.nccn.org/professionals/physician_gls/pdf/senior.pdf.

12. Biganzoli L, Wildiers H, Oakman C, Marotti L, Loibl S, Kunkler I, et al. Management of elderly patients with breast cancer: updated recommendations of the International Society of Geriatric Oncology (SIOG) and European Society of Breast Cancer Specialists (EUSOMA). Lancet Oncol. 2012;13:e148-60.

13. Coates AS, Winer EP, Goldhirsch A, Gelber RD, Gnant M, Piccart-Gebhart $\mathrm{M}$, et al. Tailoring therapies: improving the management of early breast cancer: St Gallen International Expert Consensus on the Primary Therapy of Early Breast Cancer 2015. Ann Oncol. 2015;26:1533-46.

14. Yancik R, Wesley MN, Ries LA, Havlik RJ, Edwards BK, Yates JW. Effect of age and comorbidity in postmenopausal breast cancer patients aged 55 years and older. JAMA. 2001;285:88592.

15. Kim KS, Shin KH, Choi N, Lee SW. Hypofractionated whole breast irradiation: new standard in early breast cancer after breast-conserving surgery. Radiat Oncol J. 2016;34:81-7.

16. Voduc KD, Cheang MC, Tyldesley S, Gelmon K, Nielsen TO, Kennecke H. Breast cancer subtypes and the risk of local and regional relapse. J Clin Oncol. 2010;28:1684-91.

17. Dawood S, Hu R, Homes MD, Collins LC, Schnitt SJ, Connolly $\mathrm{J}$, et al. Defining breast cancer prognosis based on molecular phenotypes: results from a large cohort study. Breast Cancer Res Treat. 2011;126:185-92.

18. Early Breast Cancer Trialists' Collaborative Group (EBCTCG), Darby S, McGale P, Correa C, Taylor C, Arriagada R, et al. Effect of radiotherapy after breast-conserving surgery on 10-year recurrence and 15-year breast cancer death: metaanalysis of individual patient data for 10,801 women in 17 randomised trials. Lancet. 2011;378:1707-16.

19. DeSantis CE, Fedewa SA, Goding Sauer A, Kramer JL, Smith RA, Jemal A. Breast cancer statistics, 2015: Convergence of incidence rates between black and white women. CA Cancer
J Clin. 2016;66:31-42.

20. Nguyen PL, Taghian AG, Katz MS, Niemierko A, Abi Raad $\mathrm{RF}$, Boon WL, et al. Breast cancer subtype approximated by estrogen receptor, progesterone receptor, and HER-2 is associated with local and distant recurrence after breast-conserving therapy. J Clin Oncol. 2008;26:2373-8.

21. Haffty BG, Yang Q, Reiss M, Kearney T, Higgins SA, Weidhaas $\mathrm{J}$, et al. Locoregional relapse and distant metastasis in conservatively managed triple negative early-stage breast cancer. J Clin Oncol. 2006;24:5652-7.

22. Sayan M, Wilson K, Nelson C, Gagne H, Rubin D, Heimann R. A novel schedule of accelerated partial breast radiation using intensity-modulated radiation therapy in elderly patients: survival and toxicity analysis of a prospective clinical trial. Radiat Oncol J. 2017;35:32-8.

23. Rakha EA, Reis-Filho JS, Baehner F, Dabbs DJ, Decker T, Eusebi $\mathrm{V}$, et al. Breast cancer prognostic classification in the molecular era: the role of histological grade. Breast Cancer Res. 2010;12:207.

24. Giuliano AE, Connolly JL, Edge SB, Mittendorf EA, Rugo HS, Solin LJ, et al. Breast Cancer-Major changes in the American Joint Committee on Cancer eighth edition cancer staging manual. CA Cancer J Clin. 2017;67:290-303.

25. Vaz-Luis I, Ottesen RA, Hughes ME, Mamet R, Burstein HJ, Edge SB, et al. Outcomes by tumor subtype and treatment pattern in women with small, node-negative breast cancer: a multi-institutional study. J Clin Oncol. 2014;32:2142-50.

26. Houvenaeghel G, Goncalves A, Classe JM, Garbay JR, Giard $\mathrm{S}$, Charytensky $\mathrm{H}$, et al. Characteristics and clinical outcome of T1 breast cancer: a multicenter retrospective cohort study. Ann Oncol. 2014;25:623-8.

27. Kasangian AA, Moretti A, Biagioli E, Bernardin E, Cordovana A, Gherardi G, et al. Does tumor size in T1-T2 early breast cancer (EBC) still have a prognostic role? J Clin Oncol. 2017;35 Suppl:Abstr e12087.

28. Fyles AW, McCready DR, Manchul LA, Trudeau ME, Merante $\mathrm{P}$, Pintilie $\mathrm{M}$, et al. Tamoxifen with or without breast irradiation in women 50 years of age or older with early breast cancer. N Engl J Med. 2004;351:963-70.

29. Hepel JT, Wazer DE. Should a woman age 70 to 80 years receive radiation after breast-conserving surgery? J Clin Oncol. 2013;31:2377-81. 